\title{
Mechanical Analysis of Tubing String in Fracturing Operation
}

\author{
Jingyuan $\mathrm{Li}^{*}$ and Zifeng $\mathrm{Li}$
}

Petroleum Engineering Institute, Yanshan University, Qinhuangdao 066004, China

\begin{abstract}
The method of fracturing of oil gas reservoir is considered as an instrumental one for maximizing the yield. Multiple loads in a well fracturing operation may compel tubing string to yield, break and/buckle in a permanent spiral, leading to severe financial deficit. Mathematical models for mechanical analysis of fracturing string in whole fracturing operation are developed on the basis of operation procedures of well fracturing, with full consideration of well trajectory, component of fracturing string, borehole fluid property, internal and external pressure, friction factor between fracturing string and well wall, tubing temperature, packer types, piston effect of packer, helical buckling effect of tubing, slip joint, etc.. These mathematical models are solved with differential methods, obtaining parameters such as tension force, torque, stress, safety factor, stability, and elongation etc. Strength calibration of the string is formed. Software for mechanical analysis of tubing string in fracturing operation is developed with Visual Basic 2008. A case study of field application is also provided.
\end{abstract}

Keywords: Tubing, fracturing, mechanics, tension, torque.

\section{INTRODUCTION}

Oil-gas reservoir fracturing is validated as an important procedure of exploration and development of oil and gas field. In this process of reservoir fracturing, the fracturing string under the influence of internal and external pressure, axial tension, bending moment, torque, temperature and other factors, might form complex stress and strain, and sometimes might damage the yield, breaking off fracture or permanent helical buckling, resulting in great economic losses. For the improvement of on-site operation, the effective analysis of stress and deformation of the fracturing string, finding effects of various parameters on the stress and deformation, optimizing parameters and design do carry great importance.

In 1980s, was introduced fracturing technology that has been reported in reference [1], and the latest developments made in this field have been presented in [2-4]. In these papers, has been focused only the technique of fracturing, lesser explaining the string mechanics. For mechanically analyzing the fracturing string, Kuru et al. studied the axial force transmission after string buckling [5]. Later Du et al. came with a preliminary mechanical analysis of fracturing string, mainly for vertical wells [6]. FEM analysis of fracturing string was performed by Wang et al. [7]. Mechanics of the fracturing string in the injecting process were probed by Li et al. [8]. These researches, however, carry great importance here still needs to conduct the mechanical analysis of the fracturing string in the entire process focusing all aspects of tripping in, setting, injecting, and tripping out.

\footnotetext{
*Address correspondence to this author at the Petroleum Engineering Institute, Yanshan University, Qinhuangdao 066004, China;

Tel/Fax: 86-335-8079-211;

E-mail: lijingyuan_ysu@hotmail.com
}

In this paper, will be presented and highlighted the mathematical models for mechanical analysis of the fracturing string in the entire process, from tripping in, setting, injecting to trip out. For this purpose, software will be developed and an example of field application will be provided.

\section{FRACTURING TYPES AND SPECIAL PROBLEMS IN FRACTURING STRING MECHANICAL ANALY- SIS}

\subsection{Fracturing Types}

It involves the processes such as mechanical single (selected) layer fracturing, mechanical separate layer fracturing, hydraulic jetting fracturing, casing injecting fracturing and blank tubing-casing injecting fracturing etc. Their usages and features of fracturing have been presented below in Table1.

\subsection{Packer Type}

For the selection of fracturing layers, packers are used to limit the fracturing sections of wells. There exist three types of packer: supporting packer, slip packer, and hydraulic pressure differential packer.

The principle of support type packer involves laying down tubing string to the bottom of well, exerting axial compressive force on the string, forcing the middle of the rubber packer thicken, and sealing annulus space; after the axial compressive force is removed, the packer restores the free state and unsetting. The advantages that make support type packer superficial are its simplicity and reliability, while the disadvantages associated with it is the limited length from the packer to the bottom of the well.

The principle of slip type packer is as follows. There exists a spring centralizer or a friction cushion block on the 
Table 1. Types, usages and features of fracturing

\begin{tabular}{|c|c|l|l|}
\hline $\begin{array}{c}\text { Serial } \\
\text { number }\end{array}$ & \multicolumn{1}{|c|}{ Name } & \multicolumn{1}{|c|}{ Usages } & Features \\
\hline \hline 1 & $\begin{array}{c}\text { Mechanical single } \\
\text { (selected) layer } \\
\text { fracturing }\end{array}$ & $\begin{array}{l}\text { Set down the string once and fracture only one layer. } \\
\text { Applicable to cased hole. }\end{array}$ & $\begin{array}{l}\text { If there is no low-pressure protection level under the fracture layer, } \\
\text { the packer and hydraulic anchor under the fracture layer may not be } \\
\text { deployed. This is known as a single layer fracturing. }\end{array}$ \\
\hline 2 & $\begin{array}{c}\text { Mechanical fracturing } \\
\text { of separate layers }\end{array}$ & $\begin{array}{l}\text { Set down the string once, fracture two or more layer } \\
\text { separately. Applicable to cased hole. }\end{array}$ & $\begin{array}{l}\text { It is necessary that there shouldn't be any layer to be protected } \\
\text { underneath the bottom fracture layer. }\end{array}$ \\
\hline 3 & $\begin{array}{c}\text { Hydraulic jet } \\
\text { fracturing }\end{array}$ & $\begin{array}{l}\text { Flush out eyehole in the wall of a well, and create } \\
\text { fractures with high-pressure jet. Applicable to open } \\
\text { hole. }\end{array}$ & A jet nozzle is connected to the bottom of tubing or coiled tubing. \\
\hline 5 & $\begin{array}{c}\text { Casing injection } \\
\text { fracturing } \\
\text { casing injection } \\
\text { fracturing }\end{array}$ & $\begin{array}{l}\text { Inject fracturing fluid from the annular space between } \\
\text { the casing and tubing, and fracturing the weakest strata } \\
\text { which has been shot above the packer. }\end{array}$ & $\begin{array}{l}\text { The packer underneath the fracturing layer protects other producing } \\
\text { layer. If there is only one layer in the whole well, the string may be } \\
\text { avoided. }\end{array}$ \\
\hline the same time.
\end{tabular}

Table 2. Fracturing procedures and key problems in tubular mechanics

\begin{tabular}{|c|c|c|c|}
\hline Sequence number & Operating procedure & Packer type & Problems considered in tubular mechanics \\
\hline 1 & Tripping in & & $\begin{array}{l}\text { The bottom of the string is free. Piston effect of the packer and the buckling effect of } \\
\text { the string need to be considered }\end{array}$ \\
\hline 2 & Setting & Slip type & $\begin{array}{l}\text { (1)When the string is raised, the bottom of the string becomes free. } \\
\text { (2) On rotating the string, the tension at the bottom of the string becomes zero. } \\
\text { (3)When the string is lowered, the packer is pressed according to the given value. The } \\
\text { string at the bottom of the packer remains in the free state. }\end{array}$ \\
\hline 3 & Injecting & & $\begin{array}{l}\text { The effect of the fluid temperature variations and the influence of high pressure inside } \\
\text { the string on the force of the string are considered. }\end{array}$ \\
\hline 4 & Unsetting & & The bottom of the string is free. The unsetting resistance is attached on the packer. \\
\hline 5 & Tripping out & & The bottom of the string is free. Piston effect of packer is considered. \\
\hline
\end{tabular}

packer(under the slips, the diameter is found to be larger than tubing string), which is always connected to the wall; during running string, the ledge is placed on the top of the transposed slot, while the rubber barrel is placed in the free state. When laying down the packer to the predetermined depth, it is begun with picking up the string, then moving the ledge to the bottom of the short slot and rotating the string for 1-3 rounds. While maintaining the torque, the string is laid down to apply compression load on the packer. Because of rotating right to the string, the ledge moves from the short slot to the long groove and the mandrel moves downward under the compressive force, the slip centrum descends to open the slip, the edge of the alloy blocking on the slip is inserted into the wall of the casing, then the rubber barrel expands under the compressive force until the two rubber barrels are both attached to the casing wall to form seal. After the test, first of all, is picked up the tubing string followed by the rubber barrel contracts, the slips withdraw and the packer is unsettling. If anchor packer is used in the drill stem, the wellbore must be regular and hard.

The working principle of hydraulic pressure differential packer: after reaching the designated location, the pressure is imposed on the string to make the packer swell.

\subsection{Injection Method}

When fracturing, it may be injected from the tubing, from the annulus, or in both ways.

\subsection{Fracturing Procedures and Main Problems in Tubular Mechanics}

Different processes of fracturing involve different stress states of the string. Therefore key problems that need to be considered also become different, as shown in Table 2.

Fracturing string is mechanically analyzed to determine the parameters along the whole string, such as tension, torque, temperature, stress, safety coefficient, stability, elongation, etc., on the basis of the operation process, wellbore trajectory, the composition of tubing string, fluid properties, internal and external pressure of tubing string, friction coefficient between the wall of wellbore and the string, string temperature, etc. The effects need to be considered are those of piston, expansion and buckling.

\section{MATHEMATICAL MODELS OF TUBING TEM- PERATURE}

The temperature of the string is reported to be different in different operations. The length and/or stress of the string are 
greatly influenced by the variations in string temperature. Therefore, while analyzing the stress state of the string, thermal stress of the string needs to be considered. During tripping in, the running speed of the string becomes lower in comparison to the increase of string temperature. So the temperature of tubing string in the wellbore is considered to be equal to the formation temperature of the point. During injecting, the temperature of the string distributes lineally along the depth if bottom hole flowing temperature could be measured; otherwise, the temperature of the string is found to be fracturing fluid temperature on the ground.

\subsection{Surface Measurements}

Before tripping in, string temperature becomes equal to its temperature on the ground

$$
T=T_{\text {surp }}
$$

\subsection{Tripping In and Tripping Out}

In tripping in and tripping out, string temperature is reported to be equal to the formation temperature

$T=T_{\text {sur } 0}+T_{\text {grad }} \int_{0}^{l} \cos \alpha \mathrm{d} l$

\subsection{Injecting}

(1) The fracturing fluid temperature on the ground is considered as the temperature of the string

$T=T_{\text {surl }}$

(2) The temperature of the string is taken as the linear function of temperature of bottom hole measurement and the fracturing fluid temperature on the surface

$$
T=T_{\text {surl }}+\left(T_{\text {bottom }}-T_{\text {surl }}\right) l / L_{\mathrm{z}}
$$

\section{HYDRAULIC PRESSURES IN TUBING AND AN- NULUS}

In the process of injecting fluid into the wells, the fluid flows to the bottom through the tubing and/or the annular space. This fluid flow can be laminar and/or turbulent. The fluid pressure in different depth is observed with variations. Since, the fluid pressure acts on the tubing, it affects the safety factor.

Fracturing fluid is reported to be a mixture of solid particles and liquid dispersion medium. There are classified about Newtonian liquid and non-Newtonian fluid. As for fluid mechanics at present, have been investigated the axial laminar flow problems of Newtonian fluid and simple nonNewtonian fluid in the pipe and annular space. Turbulence and multiphase flow researches are yet to be performed. Non-Newtonian fluid is also reported to possess thixotropic and shear thinning properties. But in the research, have not been focused these properties.

For carrying out engineering calculation, the pressure of the fluid can approximately be calculated with some assumptions.

Assumptions: (1) the fluid is Newtonian; (2) the string is concentric with the casing; (3) the effect of string joints is ignored; (4) the liquid viscosity change is ignored; (5) if the fluid is in the turbulent state, the default is a hydraulic smooth region.

In this calculation, assume that the ground pressure and rate of flow are known.

\subsection{String Inflow}

Dynamic pressure decreases gradually along the direction of flow. The reduced value of pressure is found to be proportional to the friction coefficient.

If the friction coefficient is obtained from the field test, the fixed friction coefficient is used in calculation. If the friction coefficient is not obtained, it becomes necessary to calculate friction coefficient in accordance with the fluid mechanics. The friction coefficient obtained from fieldtesting is reported to be better than that of theoretical calculation.

Reynolds number [9]

$$
\begin{aligned}
& R_{\mathrm{ei}}=\frac{\left|v_{\mathrm{i}}\right| d_{\mathrm{i}} \rho_{\mathrm{fi}}}{\mu_{\mathrm{i}}}=\frac{4 \rho_{\mathrm{fi}}\left|Q_{\mathrm{i}}\right|}{\pi \mu_{\mathrm{i}} d_{\mathrm{i}}} \\
& \quad \text { If } R_{\mathrm{ei}}<=2000, \text { in the laminar state }
\end{aligned}
$$

$\lambda_{\mathrm{i}}=\frac{64}{R_{\mathrm{ei}}}$

If $R_{\mathrm{ei}}>2000$, in the turbulent state

$\lambda_{\mathrm{i}}=\frac{0.3146}{R_{\mathrm{ei}}^{0.25}}$

The total pressure in the string

$$
\begin{aligned}
p_{\mathrm{i}} & =p_{\mathrm{i} 0}-8 \operatorname{sign}\left(Q_{\mathrm{i}}\right)\left(\frac{Q_{\mathrm{i}}}{\pi}\right)^{2} \int_{0}^{l} \frac{\lambda_{\mathrm{i}} \rho_{\mathrm{fi}}}{d_{\mathrm{i}}^{5}} \mathrm{~d} l \\
& +g \int_{0}^{l} \rho_{\mathrm{fi}} \cos \alpha \mathrm{d} l
\end{aligned}
$$

\subsection{Annular Flow}

If the annular flow friction coefficient is obtained from the field test, it is used directly. Otherwise, calculation is done according to the theory [9]

$$
R_{\mathrm{eo}}=\frac{\left|v_{\mathrm{o}}\right|\left(d_{\mathrm{w}}-d_{\mathrm{o}}\right) \rho_{\mathrm{fo}}}{\mu_{\mathrm{o}}}=\frac{4 \rho_{\mathrm{fo}}\left|Q_{\mathrm{o}}\right|}{\pi \mu_{\mathrm{o}}\left(d_{\mathrm{w}}+d_{\mathrm{o}}\right)}
$$

If $R_{\mathrm{eo}}<=2000$, in the laminar state

$\lambda_{\mathrm{o}}=\frac{96}{R_{\mathrm{eo}}}$

If $R_{\mathrm{eo}}>2000$, in the turbulent state

$\lambda_{\mathrm{o}}=\frac{0.3146}{R_{\mathrm{eo}}^{0.25}}$

Total pressure in annulus

$$
\begin{aligned}
p_{\mathrm{o}} & =p_{\mathrm{o} 0}-\operatorname{sign}\left(Q_{\mathrm{o}}\right) \int_{0}^{l} \frac{\lambda_{\mathrm{o}}}{\left(d_{\mathrm{w}}-d_{\mathrm{o}}\right)} \frac{\rho_{\mathrm{fo}} v_{\mathrm{o}}^{2}}{2} \mathrm{~d} l \\
& +g \int_{0}^{l} \rho_{\mathrm{fo}} \cos \alpha \mathrm{d} l
\end{aligned}
$$




\subsection{Throttle Valve}

For conducting some operations, such as separate-layer fracturing, the throttle valve may be installed in the tubing, which could produce differential pressure [9]

$$
\Delta p_{i}=8 \rho_{\mathrm{fi}}\left(1-\frac{d_{\mathrm{j}}^{2}}{d_{\mathrm{i}}^{2}}\right)^{2}\left(\frac{Q_{\mathrm{i}}}{\pi d_{\mathrm{j}}^{2}}\right)^{2}
$$

Because of shear thinning effect of the fracturing fluid, temperature increase while flowing down into the well and in other factors, using formula (6) or (7)、 (10) or (11) to calculate the bottom hole pressure may sometimes yield result less than the static fluid pressure, leading to fallacy.

\section{THE STRESS AND DEFORMATION OF THE STRING IN THE PROCESS OF RUNNING IN}

In the process of running in, the well bore is filled with fluid. The string is affected by a number of forces such as gravity, buoyancy, lateral contact force and friction among the sidewall, liquid viscous resistance, and so on, accompanied by temperature increase, buckling and axial deformation.

If the string moves down to the bottom and appears the helical buckling, an additional torque will be produced due to helical buckling, friction and motion, resulting into the rotation of the string or having a trend of rotating. The torque on reaching a certain value and at just its back off direction may cause tubing string twist-off. In process of tripping in, tubing string rotation may take place on drilling floor, which is the result of the torque on the string caused by buckling.

\subsection{String Tension - Torque Differential Equations}

The string involves three states in the wellbore, namely, stability, sinusoidal buckling and helical buckling. Different state of the string contradicts with different force. Since the contact force of the sinusoidal buckling between the tubing string and casing/wellbore is much less than that of helical buckling, and because of a lacking of proper calculation method, for the time being stability state is used instead of sinusoidal buckling state. If the helical buckling happens, additional resistance and torque are considered.

Suppose that the depth of helical buckling begins at $L_{\mathrm{hs}}$ and terminates at $L_{\mathrm{he}}$, in this range, there will be produced torque in the tubing string induced by helical buckling, friction and movement, and enforcing the string to rotate or having a rotating trend.

The helical buckling, rotating or the trend of rotating may produce a torque in the string below the buckling section. However, the torque value is small enough and can be neglected.

Moreover, a torque might be present in the string above the buckling section, due to the helical buckling, rotating or the trend of rotating. The farther away from the buckling section, the smaller the value of the torque will be and its distribution being unclear, but the value becomes zero at the wellhead. Assuming that torque reduction is proportional to contact force and the torque turns to zero at the wellhead.

The tension -torque differential equations [10] is

$$
\begin{aligned}
& \frac{\mathrm{d} M_{\mathrm{t}}}{\mathrm{d} l}=f_{1} R_{\mathrm{o}} N+m_{0}+\Delta M_{\mathrm{t}} \\
& \frac{\mathrm{d} F_{\mathrm{t}}}{\mathrm{d} l}+E I k_{\mathrm{b}} \frac{\mathrm{d} k_{\mathrm{b}}}{\mathrm{d} l}-f_{2}\left(N+N_{\mathrm{c}}\right) \\
& -C v-B+q \boldsymbol{k} \cdot \boldsymbol{e}_{\mathrm{t}}=0 \\
& -E I \frac{\mathrm{d}^{2} k_{\mathrm{b}}}{\mathrm{d} l^{2}}+k_{\mathrm{b}} F_{\mathrm{t}}+E I k_{\mathrm{n}}^{2} k_{\mathrm{b}}+k_{\mathrm{n}} k_{\mathrm{b}} M_{\mathrm{t}} \\
& +N_{\mathrm{n}}+f_{1} N_{\mathrm{b}}+q k \cdot e_{\mathrm{n}}=0 \\
& -\frac{\mathrm{d}\left(E I k_{\mathrm{n}} k_{\mathrm{b}}+k_{\mathrm{b}} M_{\mathrm{t}}\right)}{\mathrm{d} l}-E I k_{\mathrm{n}} \frac{\mathrm{d} k_{\mathrm{b}}}{\mathrm{d} l}+N_{\mathrm{b}} \\
& -f_{1} N_{\mathrm{n}}+q k \cdot \boldsymbol{e}_{\mathrm{b}}=0
\end{aligned}
$$

where,

$$
\begin{aligned}
& f_{1}=\frac{R_{\mathrm{o}} \omega f}{\sqrt{v^{2}+\left(R_{\mathrm{o}} \omega\right)^{2}}}, \quad f_{2}=\frac{v f}{\sqrt{v^{2}+\left(R_{\mathrm{o}} \omega\right)^{2}}}, \\
& m_{0}=2 \pi R_{\mathrm{o}}^{3} \omega\left[\frac{\tau_{0}}{\sqrt{v^{2}+\left(R_{\mathrm{o}} \omega\right)^{2}}}+\frac{2 \mu_{\mathrm{o}}}{d_{\mathrm{w}}-2 R_{\mathrm{o}}}\right] \\
& B=\frac{2 \pi R_{\mathrm{o}} \tau_{0} v}{\sqrt{v^{2}+\left(R_{\mathrm{o}} \omega\right)^{2}}}, C=\frac{2 \pi \mu_{\mathrm{o}}}{\ln \frac{d_{\mathrm{w}}}{2 R_{\mathrm{o}}}}, \\
& q=q_{0} \frac{\rho_{\mathrm{s}}-\rho_{\mathrm{fo}}}{\rho_{\mathrm{s}}}+\left(\rho_{\mathrm{fi}}-\rho_{\mathrm{fo}}\right) A_{\mathrm{i}} g,
\end{aligned}
$$

$N=\sqrt{N_{\mathrm{n}}^{2}+N_{\mathrm{b}}^{2}}$ is the contact force between the string and the wall.

In Equation (14), the first equation is the torque differential equation, the second equation being the axis tension force differential equation, the third equation as the balance equation in the principal normal direction, and the last equation as the balance equation in the binormal direction.

\subsubsection{Tripping in Process $(\omega=0, v>0)$}

The tubing under the section of helical buckling $\left(l>L_{\mathrm{he}}\right)$

$$
\Delta M_{\mathrm{t}}=N_{\mathrm{c}}=0
$$

For helical buckling section $\left(L_{\mathrm{hs}} \leq l \leq L_{\mathrm{he}}\right)$

$$
\left.\begin{array}{l}
N_{\mathrm{c}}=\frac{r_{\mathrm{b}} F_{\mathrm{t}}^{2}}{4 E I} \\
\Delta M_{\mathrm{t}}=-f R_{\mathrm{o}} \frac{r_{\mathrm{b}}^{2} F_{\mathrm{t}}^{2}}{4 E I} \sqrt{\frac{-F_{\mathrm{t}}}{2 E I}}
\end{array}\right\}
$$

The tubing above the section of helical buckling section $\left(l<L_{\mathrm{hs}}\right)$

$$
\left.\begin{array}{l}
N_{\mathrm{c}}=0 \\
\Delta M_{\mathrm{t}}=-M_{\text {ths }} \frac{N}{\int_{0}^{L_{\mathrm{hs}}} N \mathrm{~d} l}
\end{array}\right\}
$$


4.1.2. Other Processes. There is $\Delta \mathrm{M}_{t}=\mathrm{N}_{\mathrm{c}}=0$

If the tubing is not moving $(\omega=0, v=0)$, then taking $f=0$.

Eq. (14) not only applies for tripping in process, but also applies to other processes.

\subsection{Continuity Conditions}

If some larger diameter tools are reported to be present on the string, such as a packer, then piston effect cannot be neglected, so the force caused by piston effect becomes necessary to be added in the calculation [10]

$$
\left.F_{\mathrm{t}}\right|_{l=l_{\mathrm{p} j}^{-}}=\left.F_{\mathrm{t}}\right|_{l=l_{\mathrm{p} j}^{+}}+F_{\mathrm{p} j}
$$

\subsection{Boundary Conditions}

\subsubsection{Monitoring Friction Coefficient, Stress Condition, Contact force between the String and wellbore}

If the hook load is measured, it can be used to monitor friction coefficient between the string and wellbore, stress condition of the string and the contact force

$$
\left.\begin{array}{l}
F_{\mathrm{t}}(L)=0 \\
M_{\mathrm{t}}(L)=0 \\
F_{\mathrm{t}}(0)=W_{\mathrm{oh}} \\
M_{\mathrm{t}}(0)=0
\end{array}\right\}
$$

If the friction coefficient of the whole or any part of well is assumed as an unknown constant, then any kinds of load measured on the ground (hook load, rotating torque) can be used to calculate the friction coefficient between the string and well bore.

\subsubsection{Prediction of Stress State and Contact Force between the Tubing String and Sidewall}

At the lower end of the string, both the axial tension and torque are reported to be zero

$$
\left.\begin{array}{l}
F_{\mathrm{t}}(L)=0 \\
M_{\mathrm{t}}(L)=0
\end{array}\right\}
$$

\subsection{Identification the State of String Self-locking}

According to the result of nonlinear helical buckling without gravity ${ }^{[10]}$, the string self-locking condition is as follows

$$
F_{\mathrm{t}}<=-\frac{4 E I}{3 \sqrt{3} r_{\mathrm{b}}^{2}}
$$

\subsection{Axial Deformation of the String}

Tubing string will be deformed under axial tension, buckling and temperature change

$$
\begin{aligned}
& s=\int_{0}^{l}\left[\frac{\sigma_{\mathrm{t}}-\mu_{\mathrm{p}}\left(\sigma_{\theta}+\sigma_{\mathrm{r}}\right)}{E}+\gamma\left(T-T_{\text {surp }}\right)+\varepsilon_{\mathrm{h}}\right] \mathrm{d} l \\
& \varepsilon_{\mathrm{h}}=\left\{\begin{array}{lc}
\sqrt{1+\frac{r_{\mathrm{b}}^{2} F_{\mathrm{t}}}{2 E I}-1} & \left(L_{\mathrm{hs}} \leq l \leq L_{\mathrm{he}}\right) \\
0 & \text { other }
\end{array}\right\}
\end{aligned}
$$

\section{THE STRING FORCE AND DEFORMATION IN SETTING PROCESS}

Consider three types of packers: support, anchor and hydraulic pressure differential.

\subsection{Support Packer}

Axial compressive force at the packer is calculated equal to or greater than the given value of axial compressive force. In Eq. (14), taking $\omega=0$ and $v>0$, and the modifying boundary conditions of Eq. (20) as follows

$\left.\begin{array}{l}F_{\mathrm{t}}\left(L_{\mathrm{p}}\right)=-F_{\mathrm{p}} \\ M_{\mathrm{t}}(L)=0\end{array}\right\}$

\subsection{Slip Packer}

In the process of slip packer setting: (1) string is picked up, and the ledge is forced to slide down in the short slot; (2) rotating string makes ledge converse; (3) by laying down string, the ledge is made to slide up in the long slot, locking the bottom of the packer, meanwhile, the packer starts expanding to seal wellbore; (4) the pressure in the string is increased, the hydraulic anchor is opened and stuck into the sidewall to maintain rubber barrel pressure.

\subsubsection{Tripping Out}

Now picking up the whole tubing string, in Eq. (14), taking $\omega=0$ and $v<0$.

\subsubsection{Rotating String}

Now rotating tubing string, in Eq. (14), taking $\omega>0$ and $v=0$.

\subsubsection{Tripping In}

The effect of slips leads to the division of string into upper and lower parts. Differential equation is still Eq. (14). The state of motion is $\omega=0$ at the upper $\left(0 \leq l \leq L_{\mathrm{p}}\right)$, boundary conditions

$\left.\begin{array}{l}F_{\mathrm{t}}\left(L_{\mathrm{p}}^{+}\right)=F_{\mathrm{t}}\left(L_{\mathrm{p}}^{-}\right)+F_{\mathrm{pl}} \\ M_{\mathrm{t}}\left(L_{\mathrm{p}}\right)=0\end{array}\right\}$

At the lower end of the string $\left(L_{\mathrm{p}}<l \leq L\right)$, and its movement trend $\omega=0$ and $v>0$, boundary conditions

$\left.\begin{array}{l}F_{\mathrm{t}}(L)=0 \\ M_{\mathrm{t}}(L)=0\end{array}\right\}$

\subsubsection{Opening Hydraulic Anchor}

After the tripping in of the tubing string, the effect of the slips makes it difficult for the packer to slide freely in the well. The change of internal and external pressure causes the string stress and the axis shape to change.

(1) Tubing string without buckling. The string is expanded by internal pressure and compressed by external pressure in the free state. The effect of the packer does not let the length of the string elongate or shorten, that is reported to be equivalent to addition of an axial tension on the string

$F_{\mathrm{e}}=\left(1-2 \mu_{\mathrm{p}}\right)\left[-\left(p_{\text {ia }}-p_{\text {is }}\right) A_{\mathrm{i}}+\left(p_{\text {oa }}-p_{\text {os }}\right) A_{\mathrm{o}}\right]$ 
(2) The tubular buckling occurs. In case, the tubular buckling occurs, the packer axial tension $-F_{\mathrm{p}}$ and string axial elongation $s_{\mathrm{ps}}$ at the packer (taking shortening as negative) need to be calculated first in the slips setting process under the internal pressure $p_{\text {is }}$ and the external pressure $p_{\text {os }}$. Then, should be calculated the axial force $F_{\mathrm{pa}}$ to get the elongation $s_{\mathrm{ps}}$ under the conditions of internal pressure $p_{\text {ia }}$ and outside pressure $p_{\mathrm{oa}}$. This process requires trial calculation.

\subsection{Hydraulic Pressure Differential Packer}

Throw a ball into the tubing to add pressure to the tubing directly. When the pressure reaches a certain value, the hydraulic anchor and packer set in the casing.

\section{FORCES AND DEFORMATION IN THE PROCESS OF INJECTING}

After tripping in, the tubing is generally moved up and down, and packer is set down. The tubing movements bring a decrease in the friction between the tubing and casing. The distribution of friction between tubing and casing is still unclear. In order to calculate easily, the effect of friction is ignored.

After the above mentioned simplification, the tubing would be subjected to the gravity, the external pressure of the annulus fluid, the internal pressure of tubing fluid, the contact force with wellbore and the supporting force of packer, besides, bending stress of tubing bending with the hole, thermal stress caused by temperature change and buckling bending stress. Different processes have different stress of tubing, depending upon the composition of the string, boundary conditions, etc. In the hydraulic jet fracturing, the string with no packer moves up and down. The stress and deformation of string could be calculated using equation (14). Mechanical models of other four kinds in the process of injecting are as follows.

\subsection{Tubing Tension-torque Differential Equation}

$$
\frac{\mathrm{d} F_{\mathrm{t}}}{\mathrm{d} l}+E I k_{\mathrm{b}} \frac{\mathrm{d} k_{\mathrm{b}}}{\mathrm{d} l}+q \boldsymbol{k} \cdot \boldsymbol{e}_{\mathrm{t}}=0
$$

\subsection{Boundary Conditions}

\subsubsection{Mechanical Single Layer Fracture}

(1) Tubing anchored. This working condition refers to the normal condition of mechanical single layer fracture. Its characteristics is that the total elongation of the tubing underground is the same as that of setting

$$
s(L)=s_{0}(L)
$$

Sometimes, a slip joint is added above the packer. In setting process, there lies a compressive force on the slip joint. In injecting process, the slip joint may withstand tension, compression, or may also be free

$$
\left.\begin{array}{l}
s(L)=s_{0}(L) \quad\left[F_{\mathrm{t}}(L)<0\right] \\
F_{\mathrm{t}}(L)=0 \\
s(L)+s_{\text {slip }}=s_{0}(L) \quad\left[F_{\mathrm{t}}(L)>0\right]
\end{array}\right\}
$$

(2) Failure of packer and anchoring equipment. In case, the packer and anchoring equipment both fail calculation of the deformation and stress becomes equal to that of the static state, the change is observed only in the internal and external pressures.

$$
F_{\mathrm{t}}(L)=0
$$

(3) Single-packer setting without anchor. This working condition involves installation of a packer above the reservoir without anchor and packer seals and may slide along the well bore. Its characteristics is that packer may slide along the well bore under the fracturing fluid pressure in the process of fracturing at the bottom of tubing

$$
F_{\mathrm{t}}(L)=-\frac{\pi}{4} p_{\mathrm{fb}}\left(d_{\mathrm{w}}^{2}-d_{\mathrm{i}}^{2}\right)
$$

If the liquid is injected into the annular, it starts the casing injecting fracturing

\subsubsection{Mechanical Selective Layer and Separate Layer Fracturing}

The working condition refers to proper functioning of both the upper and lower hydraulic anchors. The elongations of underground tubing at the two hydraulic anchors are characterized to be the same as setting in the processes of injection and anti-handling

$$
\left\{\begin{array}{l}
s\left(L_{1}\right)=s_{0}\left(L_{1}\right) \\
s\left(L_{2}\right)=s_{0}\left(L_{2}\right)
\end{array}\right.
$$

Sometimes, a slip joint is added at the upper end of the packer. In setting, there exists a compressive force on the slip joint. In injecting, the slip joint may withstand tension, compression, or might also be free

$$
\left.\begin{array}{l}
s\left(L_{1}\right)=s_{0}\left(L_{1}\right) \quad\left[F_{\mathrm{t}}\left(L_{1}\right)<0\right] \\
F_{\mathrm{t}}\left(L_{1}\right)=0 \\
s\left(L_{1}\right)+s_{\text {slip }}=s_{0}\left(L_{1}\right) \quad\left[F_{\mathrm{t}}\left(L_{1}\right)>0\right.
\end{array}\right\}
$$

\subsubsection{Blank Tubing and Casing Injecting Fracturing}

The working condition refers to the injecting of the blank tubing into both the annulus and tubing at the same time. The bottom of string is reported to be free

$$
F_{\mathrm{t}}(L)=0
$$

\section{FORCE AND DEFORMATION OF STRING DUR- ING UNSETTING AND TRIPPING OUT}

In the processes of unsetting and tripping out, the wellbore is filled with liquid. The string force possesses gravity, buoyancy, lateral contact force, friction, liquid viscous drag, etc. At the same time, this string force also causes string bending and axial deformation. In the process of unsetting, an unsetting tension is exerted at the packer, but when tripping out, the tension becomes zero, the piston force of packer has to be considered.

\subsection{Unsetting}

In unsetting process, there lies a tension increment at the packer

$\left.\begin{array}{l}F_{\mathrm{t}}\left(L_{\mathrm{p}}^{+}\right)=F_{\mathrm{t}}\left(L_{\mathrm{p}}^{-}\right)-F_{\mathrm{pu}} \\ F_{\mathrm{t}}(L)=0 \\ M_{\mathrm{t}}(L)=0\end{array}\right\}$




\subsection{Tripping Out}

Take $v<0$ in Eq. (14).

\section{STRENGTH CALIBRATION OF THE STRING}

Strength verification can be made after computing string tension, torque, internal pressure and external pressure.

Both the tube bodies and joints are significant enough to be considered in the strength verification for the string. The tube bodies may be checked through mechanical analysis, while joints, due to their complexity of the stress will be ignored in the paper.

\subsection{Tensile Stress}

The tensile stress caused by axial tension force and internal and external pressures has been represented by the following equation

$\sigma_{\mathrm{t}}=\frac{F_{\mathrm{t}}+p_{\mathrm{i}} A_{\mathrm{i}}-p_{\mathrm{o}} A_{\mathrm{o}}}{A}$

\subsection{Shear Stress}

The shear stress caused by the torque is

$$
\tau=\frac{M_{\mathrm{t}} r}{J}
$$

\subsection{Bending Stress} is

The bending stress caused by the bending of the wellbore

$$
\sigma_{\mathrm{b}}=E k_{\mathrm{b}} r
$$

The bending stress caused by helical buckling is

$\sigma_{\mathrm{bc}}=-\frac{r_{\mathrm{b}} F_{\mathrm{t}} r}{2 I}$

\subsection{Radial Stress and Tangential Stress}

The radial stress and tangential stress caused by internal pressure and external pressure are

$$
\left.\begin{array}{c}
\sigma_{\mathrm{r}}=\frac{p_{\mathrm{i}} R_{\mathrm{i}}^{2}-p_{\mathrm{o}} R_{\mathrm{o}}^{2}}{R_{\mathrm{o}}^{2}-R_{\mathrm{i}}^{2}}-\frac{\left(p_{\mathrm{i}}-p_{\mathrm{o}}\right) R_{\mathrm{i}}^{2} R_{\mathrm{o}}^{2}}{\left(R_{\mathrm{o}}^{2}-R_{\mathrm{i}}^{2}\right) r^{2}} \\
\sigma_{\grave{\mathrm{e}}}=\frac{p_{\mathrm{i}} R_{\mathrm{i}}^{2}-p_{\mathrm{o}} R_{\mathrm{o}}^{2}}{R_{\mathrm{o}}^{2}-R_{\mathrm{i}}^{2}}+\frac{\left(p_{\mathrm{i}}-p_{\mathrm{o}}\right) R_{\mathrm{i}}^{2} R_{\mathrm{o}}^{2}}{\left(R_{\mathrm{o}}^{2}-R_{\mathrm{i}}^{2}\right) r^{2}}
\end{array}\right\}
$$

\subsection{Stress Intensity}

For tension part of the string

$$
\sigma_{\mathrm{i}}=\sqrt{\begin{array}{l}
\left(\sigma_{\mathrm{t}}+\sigma_{\mathrm{b}}\right)^{2}+\sigma_{\mathrm{r}}^{2}+\sigma_{\theta}^{2}-\left[\left(\sigma_{\mathrm{t}}+\sigma_{\mathrm{b}}\right) \sigma_{\mathrm{r}}\right. \\
\left.+\sigma_{\mathrm{r}} \sigma_{\theta}+\sigma_{\theta}\left(\sigma_{\mathrm{t}}+\sigma_{\mathrm{b}}\right)\right]+3 \tau^{2}
\end{array}}
$$

For compress and not buckling part of the string

$$
\sigma_{\mathrm{i}}=\sqrt{\begin{array}{l}
\left(\sigma_{\mathrm{t}}-\sigma_{\mathrm{b}}\right)^{2}+\sigma_{\mathrm{r}}^{2}+\sigma_{\theta}^{2}-\left[\left(\sigma_{\mathrm{t}}-\sigma_{\mathrm{b}}\right) \sigma_{\mathrm{r}}\right. \\
\left.+\sigma_{\mathrm{r}} \sigma_{\theta}+\sigma_{\theta}\left(\sigma_{\mathrm{t}}-\sigma_{\mathrm{b}}\right)\right]+3 \tau^{2}
\end{array}}
$$

For compress and buckling part of the string

$$
\sigma_{\mathrm{i}}=\sqrt{\begin{array}{l}
\left(\sigma_{\mathrm{t}}-\sigma_{\mathrm{b}}-\sigma_{\mathrm{bc}}\right)^{2}+\sigma_{\mathrm{r}}^{2}+\sigma_{\theta}^{2} \\
-\left[\left(\sigma_{\mathrm{t}}-\sigma_{\mathrm{b}}-\sigma_{\mathrm{bc}}\right) \sigma_{\mathrm{r}}+\sigma_{\mathrm{r}} \sigma_{\theta}\right. \\
\left.+\sigma_{\theta}\left(\sigma_{\mathrm{t}}-\sigma_{\mathrm{b}}-\sigma_{\mathrm{bc}}\right)\right]+3 \tau^{2}
\end{array}}
$$

\subsection{Safety Factor}

Since the stress intensity from the tubing inner wall to outer wall is found to be changing, so it becomes necessary to take the maximum value for the checking of the string

$$
n=\frac{\sigma_{\mathrm{s}}}{\sigma_{\mathrm{i} \max }}
$$

Theoretically, Equation (44) calculates the minimum safety coefficient of the section, which is found to be equal or lesser than actual overall static safety coefficient. However, factors of fatigue, dynamic load, and scratches may lead to a deficit in the actual safety coefficient. Therefore, the real safety coefficient calculation still poses as a challenge that needs to be overcome.

\section{SOFTWARE DEVELOPMENT AND APPLICATION}

According to considering the theories presented above, and on the basis of literature [11], has been developed the fracturing tubular mechanical analysis software has been developed with the programs such as Visual Basic 2008, Teechart and Office. The main functions of the software include: (1) the wellbore trajectory calculation and visualization; (2) mechanical analysis of tubing string in the processes of tripping out and tripping in; (3) mechanical analysis of tubing string in the process of fracturing; (4) analysis of down hole condition. The input parameters of the system include: (1) well trajectory; (2) fracturing string combination; (3) casing combination; (4) sliding friction coefficient between fracturing string and casing/wellbore; (5) fluid property in the string and annulus; (6) fracturing operation parameters. The output parameters are: (1) well bore trajectory data and three-dimensional map; (2) in the process of tripping, in any case, calculation of string tension, torque, lateral contact force, safety coefficient, stability and elongation; (3) in the process of fracturing, annulus pressure, string internal pressure, tension, stability and safety coefficient and elongation, etc.; (4) true friction coefficient between testing string and casing/wellbore.

In the initial phase, this software has been utilized in oilfield. From 2009, more than 1000 fracturing strings have been analyzed and tested using the software and no string breaking problem has been reported so far in industrial practice.

\subsection{Example 1: S-1 Well}

S-1 well is a deep well, the parameters of which are as follows: inclination data in Table $\mathbf{3}$, combination of fracturing string in Table 4, combination of casing in Table 5 , and fracturing parameters in Table $\mathbf{6}$. The friction coefficient is 0.5 when tripping out, while it is reported to be 0.35 when tripping in. The rotating friction coefficient is 0.45 . The fluid density inside and outside the string is calculate as $1220 \mathrm{~kg} / \mathrm{m}^{3}$ having a viscosity of $0.01 \mathrm{~Pa}$.s. The surface temperature is reported to be $16^{\circ} \mathrm{C}$ and the geothermal gradient is found to be $2.2^{\circ} \mathrm{C} / 100 \mathrm{~m}$. 
Table 3. Inclination data

\begin{tabular}{|c|c|c|c|}
\hline Sequence number & Depth measurement $(\mathbf{m})$ & Inclination $\left(^{\circ}\right)$ & Azimuth $\left(^{\circ}\right)$ \\
\hline \hline 1 & 1172 & 0.469 & 294.300 \\
\hline 2 & 1522 & 0.313 & 286.840 \\
\hline 3 & 2022 & 0.412 & 185.600 \\
\hline 4 & 2522 & 0.644 & 283.190 \\
\hline 5 & 3022 & 0.554 & 268.920 \\
\hline 6 & 3522 & 0.551 & 15.804 \\
\hline 7 & 4022 & 0.494 & 103.770 \\
\hline 9 & 4522 & 0.820 & 207.050 \\
\hline 10 & 5022 & 0.767 & 207.000 \\
\hline
\end{tabular}

Table 4. Well fracturing string

\begin{tabular}{|c|c|c|c|c|c|c|c|}
\hline Sequence number & Name & $\begin{array}{l}\text { Outside diameter } \\
(\mathbf{m})\end{array}$ & $\begin{array}{l}\text { Inside diameter } \\
\text { (m) }\end{array}$ & Wall thickness (m) & Steel grade & $\begin{array}{c}\text { Linear mass } \\
(\mathrm{kg} / \mathrm{m})\end{array}$ & Length (m) \\
\hline 1 & Tubing & 0.0889 & 0.0760 & 0.0065 & P-110 & 15.18 & 4997.18 \\
\hline 3 & Tubing & 0.0730 & 0.0620 & 0.0055 & P-110 & 9.520 & 760.77 \\
\hline 4 & Change over & 0.0980 & 0.0450 & 0.0265 & P-110 & 46.00 & 0.310 \\
\hline 6 & RTTS packer & 0.1110 & 0.0460 & 0.0325 & P-110 & 62.00 & 1.180 \\
\hline 7 & Tubing & 0.0730 & 0.0620 & 0.0055 & P-110 & 9.52 & 9.630 \\
\hline
\end{tabular}

Table 5. Casing string

\begin{tabular}{|c|c|c|c|c|c|c|}
\hline Sequence number & Name & Outside diameter $(\mathbf{m})$ & Inside diameter $(\mathbf{m})$ & Wall thickness $(\mathbf{m})$ & Linear mass $(\mathbf{k g} / \mathbf{m})$ & Length $(\mathbf{m})$ \\
\hline \hline 1 & casing & 0.2445 & 0.2205 & 0.0120 & 69.940 & 5250 \\
\hline 2 & casing & 0.2064 & 0.1718 & 0.0017 & - \\
\hline
\end{tabular}

Table 6. Fracturing parameters

\begin{tabular}{|c|c|}
\hline Reservoir depth Measured(m) & $\mathbf{5 7 7 7}$ \\
\hline \hline Reservoir temperature $\left({ }^{\circ} \mathrm{C}\right)$ & 127.094 \\
\hline Reservoir pressure $(\mathrm{MPa})$ & 69.64 \\
\hline Reservoir fluid density $\left(\mathrm{kg} / \mathrm{m}^{3}\right)$ & 861.00 \\
\hline Reservoir fluid viscosity $(\mathrm{Pa} \cdot \mathrm{s})$ & 0.0100 \\
\hline Maximum produced rate of flow $\left(\mathrm{m}^{3} / \mathrm{s}\right)$ & 0.0010 \\
\hline Fracturing fluid density $\left(\mathrm{kg} / \mathrm{m}^{3}\right)$ & 1020.00 \\
\hline Fracturing fluid viscosity $(\mathrm{Pa} \cdot \mathrm{s})$ & 0.0100 \\
\hline Fracturing fluid temperature at $\mathrm{wellhead}\left({ }^{\circ} \mathrm{C}\right)$ & 20.00 \\
\hline Fracturing fluid temperature at the bottom $\left({ }^{\circ} \mathrm{C}\right)$ & 80.00 \\
\hline Tripping in velocity $(\mathrm{m} / \mathrm{s})$ & 0.30 \\
\hline Tripping out velocity $(\mathrm{m} / \mathrm{s})$ & 0.30 \\
\hline Fracturing type & Single packer and single layer \\
\hline
\end{tabular}


Table 6. Contd....

\begin{tabular}{|c|c|}
\hline Reservoir depth Measured(m) & $\mathbf{5 7 7 7}$ \\
\hline \hline Packer type & Slip \\
\hline Axial clamping compress force of packer $(\mathrm{kN})$ & 50.00 \\
\hline Internal pressure at wellhead $(\mathrm{MPa})$ & 66.30 \\
\hline Flow rate in tubing $\left(\mathrm{m}^{3} / \mathrm{s}\right)$ & 0.0910 \\
\hline Friction coefficient in tubing & 0.002 \\
\hline Annular pressure at wellhead $(\mathrm{MPa})$ & 0 \\
\hline Flow rate in annulus $\left(\mathrm{m}^{3} / \mathrm{s}\right)$ & 0 \\
\hline Friction coefficient in annulus & 0 \\
\hline Axial additional tension on packer when unsetting $(\mathrm{kN})$ & 50.00 \\
\hline Tool allowable curvature $(\% / \mathrm{m})$ & 1.00 \\
\hline
\end{tabular}

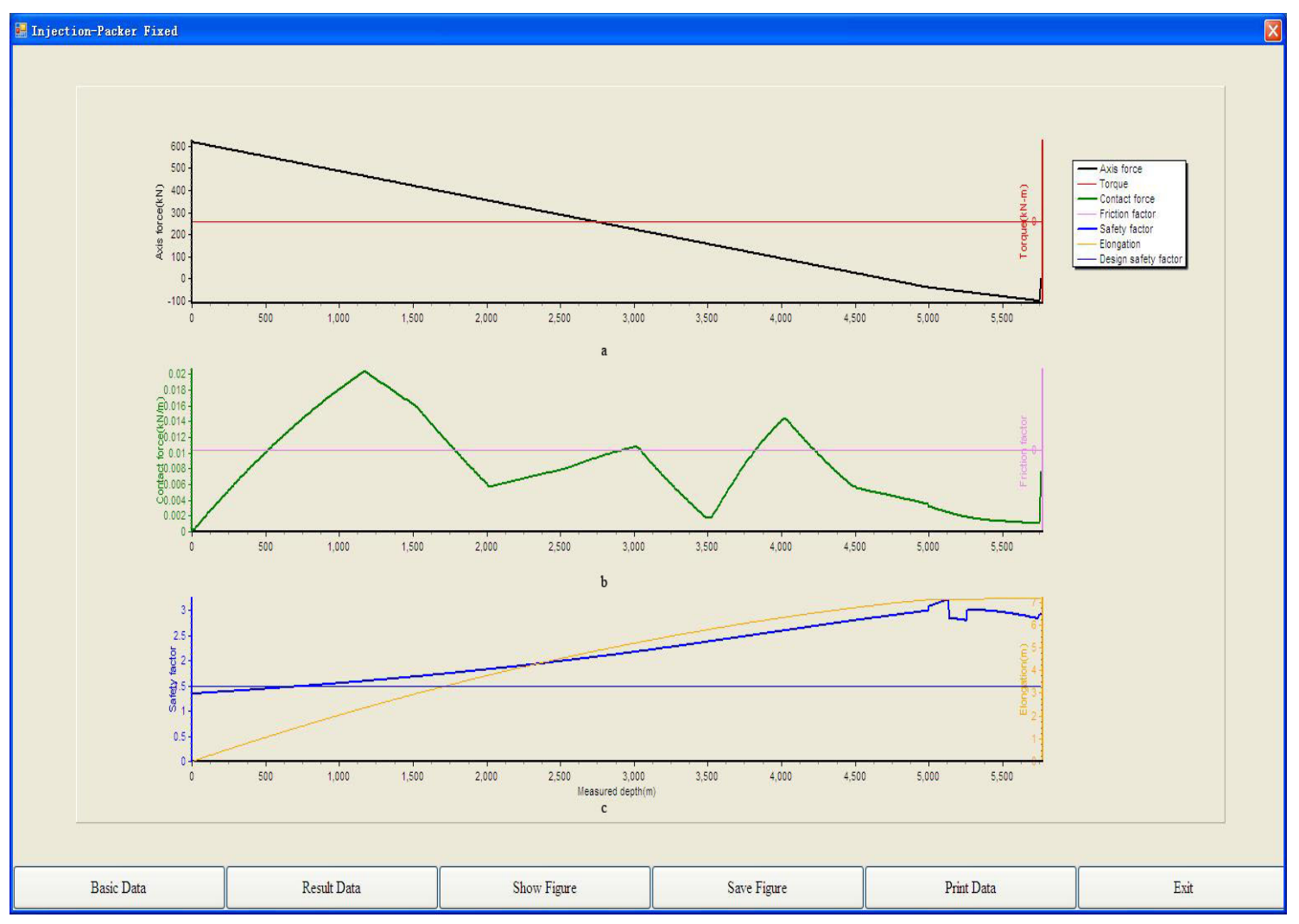

Fig. (1). Mechanical conditions of S-1 well string in injection.

Table 7. Result of mechanical analysis in the whole fracturing procedures.

\begin{tabular}{|c|c|c|c|}
\hline Operating procedure & Minimum safety factor & $\begin{array}{c}\text { Location of the minimum safety factor } \\
\text { occurs(m) }\end{array}$ & String elongation (m) \\
\hline \hline Running string to the depth of operation & 1.79 & Well head & 10.07 \\
\hline Packer setting & 2.20 & Well head & 7.53 \\
\hline Fracturing - packer anchored & 1.34 & Well head & -6.18 \\
\hline Fracturing - packer slipping & 0.51 & Bottom buckled section & 11.29 \\
\hline Packer unsetting & 1.57 & Well head & 10.37 \\
\hline Start tripping out & 1.69 & Well head & \\
\hline
\end{tabular}




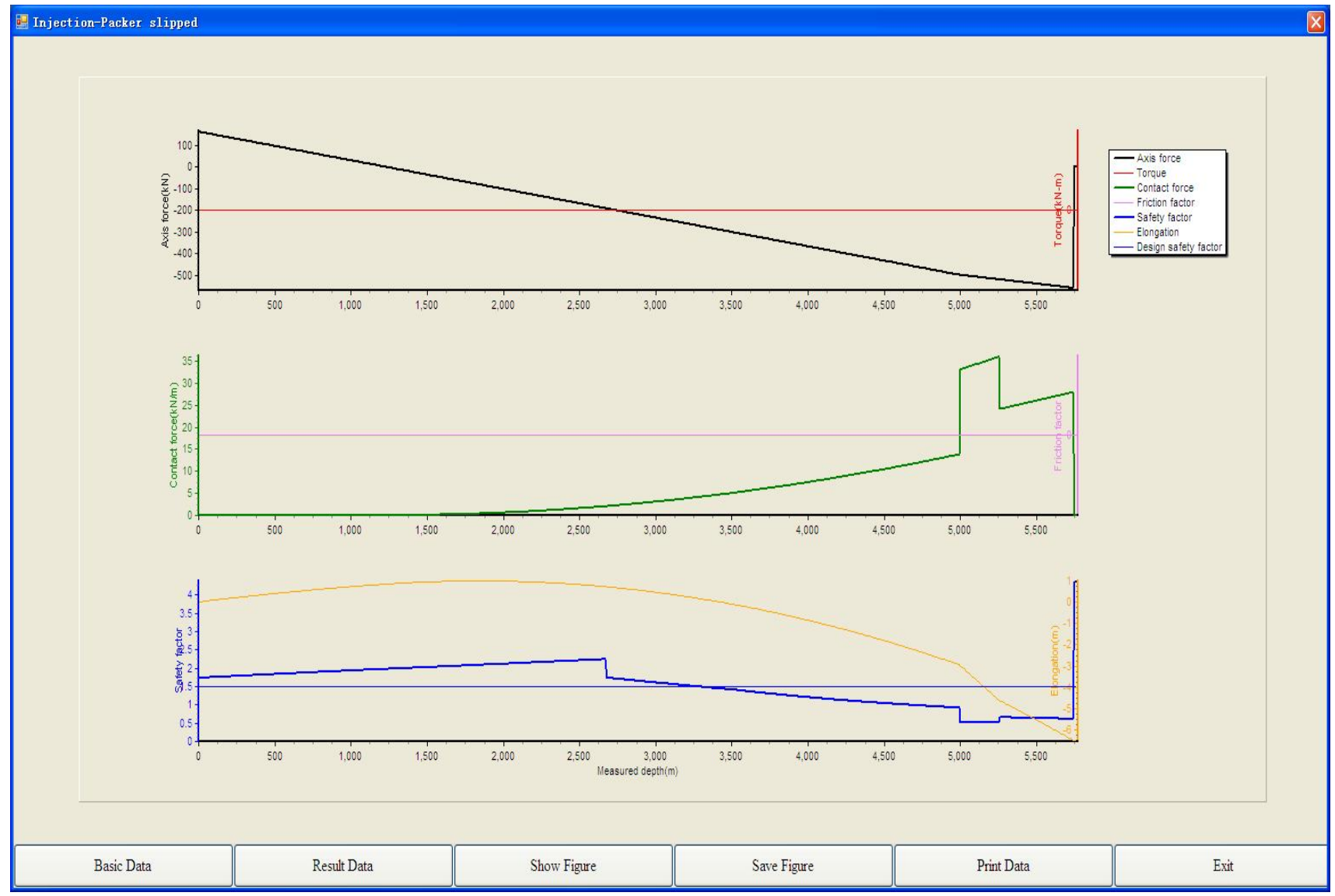

Fig. (2). Shows the mechanical conditions of S-1 well string while packer slipping upwards.

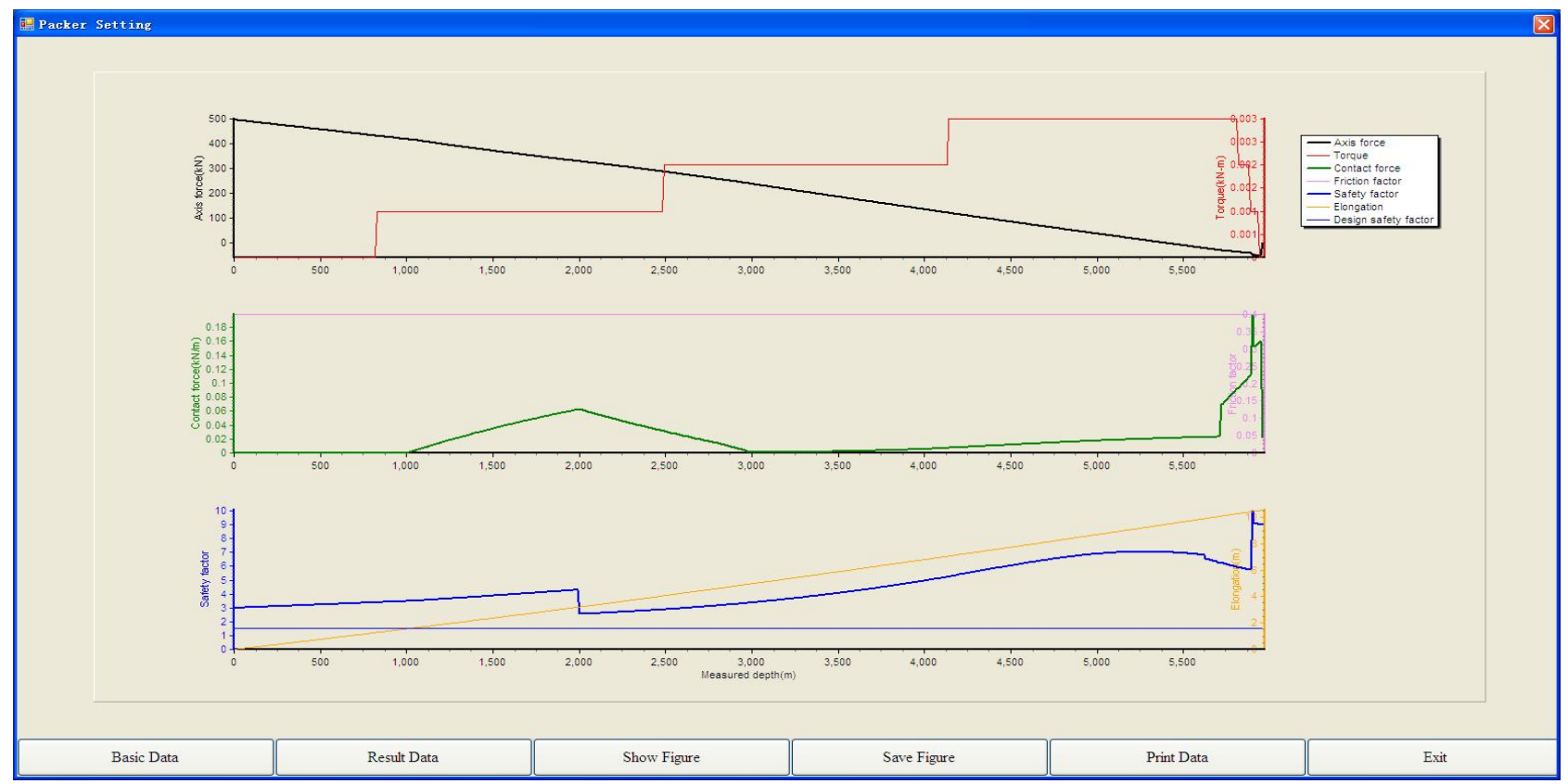

Fig. (3). Mechanical conditions of T-1 well string in packer setting.

In Fig. (1a), has been shown the dependence of the axial force and torque on the measured depth. In this figure, the abscissa is shown as measured depth, the left ordinate as the axial force, while the right ordinate has been reported as torque. Fig. (1b) highlights the distribution of the contact force and friction factor over the measured depth. In this figure, the abscissa is measured depth, the left ordinate is contact force, and the right ordinate has been presented as friction factor. Fig. (1c) shows the dependence of the safety factor and elongation upon the measured depth. Here, the 


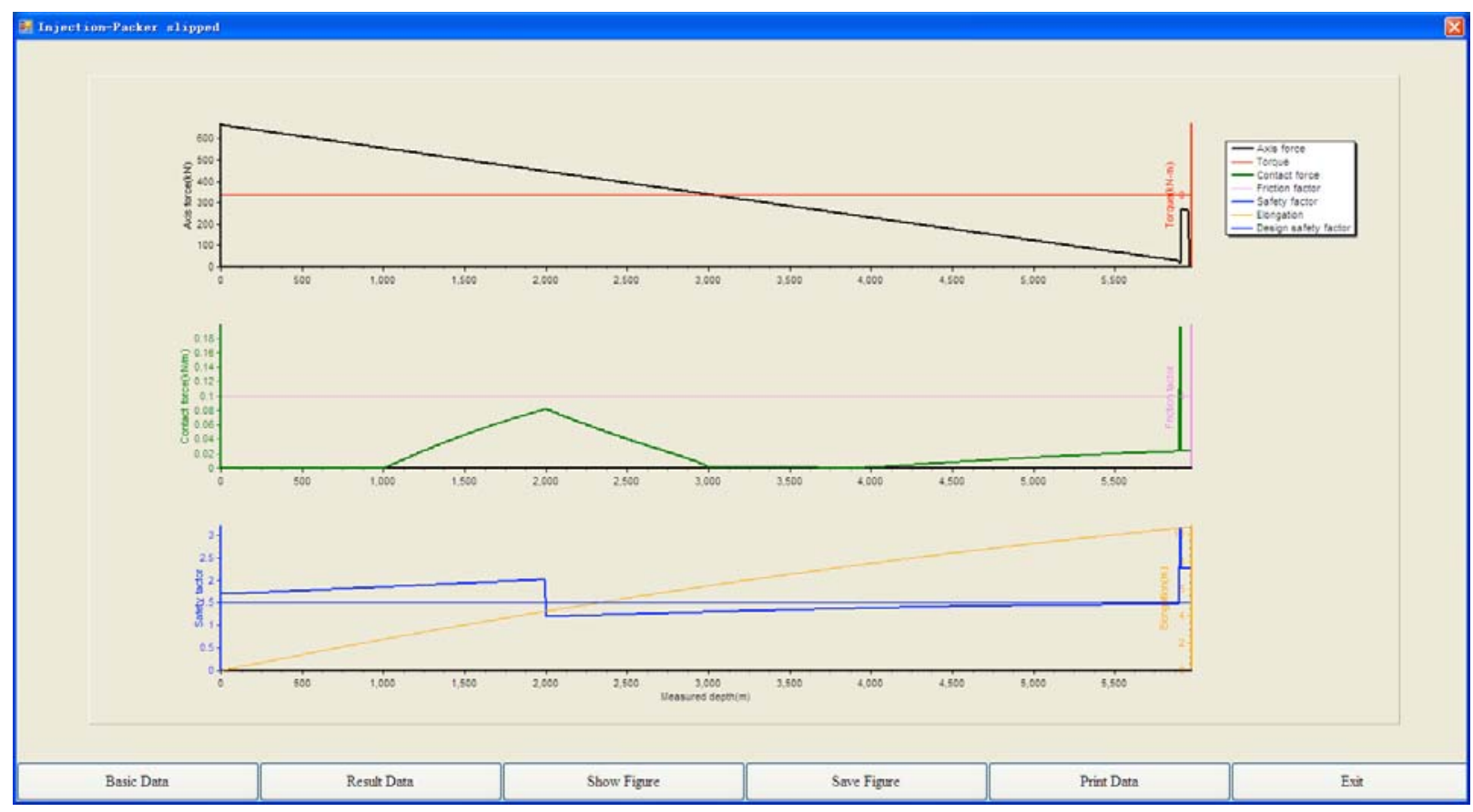

Fig. (4). Mechanical conditions of T-1 well string in injection.

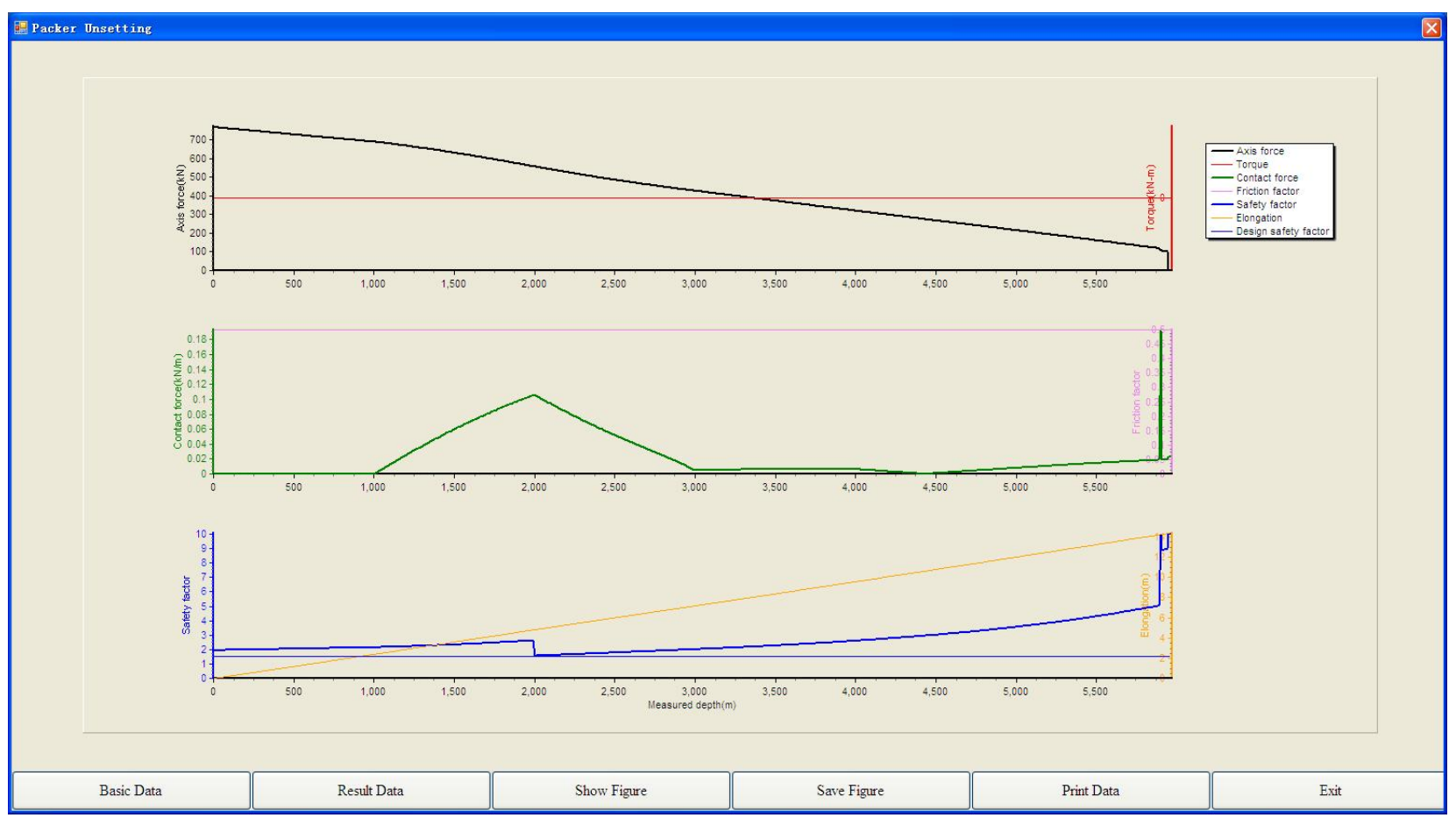

Fig. (5). Mechanical conditions of T-1 well string in packer unsetting.

abscissa is measured depth, the left ordinate is safety factor, the right ordinate is elongation.

In Table. 7, have been highlighted the minimum safety coefficient of the string and the total elongation of the string in each work process. Fig. (1) defines the mechanical state of string in injection process. Fig. (2) comes up with the mechanics state of string when packer slides up. The overall conclusion is that the safe coefficient of the string is not high enough. Once the anchor of the packer fails, string buckling failure will take place.

\subsection{Example 2: T-1 Well}

$\mathrm{T}-1$ well is a vertical well with inclination $13^{\circ}$ at finished depth $6100 \mathrm{~m}$. Two packers are used to select a layer. The mechanical conditions of string in packer setting, injection and packer unsetting are shown in Figs. (3 and $\mathbf{4}$ ) and Fig. (5) respectively. In Fig. (3), the string has been shown under helical buckling at the bottom inducing light torque. Fig. (4) shows that the reduction of temperature produces tension force in the part between two packers, and the safety factor from $2000 \mathrm{~m}$ to $5900 \mathrm{~m}$ is a little larger than 1 . It is 
suggested that the string from $2000 \mathrm{~m}$ to $5900 \mathrm{~m}$ should be strengthened.

\section{CONCLUSION}

(1) The mathematical models for mechanical analysis of tubing string in the whole process from the string tripping in, setting down, injecting to tripping out are established in this paper.

(2) The software of mechanical analysis of tubing string in fracturing operation is developed.

(3) More than 1000 fracturing strings have been evaluated and no string break problem was recorded.

\section{CONFLICT OF INTEREST}

The authors confirm that this article content has no conflicts of interest.

\section{ACKNOWLEDGEMENTS}

The paper is supported by NSFC No. 51244004 and Open Fund of EOR Key Laboratory of Ministry of Education of China at Northeast Petroleum University. The authors gratefully acknowledge Dr. Zirui Li for polishing this paper's English.

\section{NOMENCLATURE}

\begin{tabular}{|c|c|}
\hline$A$ & $=$ string cross-sectional area $\left(A=A_{\mathrm{o}}-A_{\mathrm{i}}\right)$ \\
\hline$A_{\mathrm{i}}$ & $=$ string inner area \\
\hline$A_{\mathrm{o}}$ & $=$ string outer area \\
\hline$d_{\mathrm{w}}$ & $=$ well diameter \\
\hline$E$ & $=$ young's elastic modulus \\
\hline$d_{\mathrm{i}}$ & $=$ inner diameter of string \\
\hline$d_{\mathrm{j}}$ & $=$ throttle valve diameter \\
\hline$d_{\mathrm{o}}$ & $=$ outer diameter of string \\
\hline $\boldsymbol{e}_{\mathrm{t}}, \boldsymbol{e}_{\mathrm{n}}, \boldsymbol{e}_{\mathrm{b}}$ & $\begin{array}{l}\text { direction of the tangent, the principal normal, } \\
\text { binormal of the string deformation }\end{array}$ \\
\hline$F_{\mathrm{e}}$ & $=\begin{array}{l}\text { axial tension caused by change of internal and external } \\
\text { pressure }\end{array}$ \\
\hline$F_{\mathrm{p}}$ & $=$ axial compressive force on packer to make it work \\
\hline$F_{\mathrm{pa}}$ & $=$ axial tensile force at packer in setting \\
\hline$F_{\mathrm{p} j}$ & $=$ piston force at packer $j$ \\
\hline$F_{\mathrm{pl}}$ & $\begin{array}{l}=\text { axial friction force between string and wellbore to } \\
\text { make packer setting }\end{array}$ \\
\hline$F_{\mathrm{pu}}$ & $=$ tension force for packer unsetting \\
\hline$F_{\mathrm{t}}$ & $=$ tension force \\
\hline$f$ & $=\begin{array}{l}\text { sliding friction coefficient between string and well } \\
\text { bore }\end{array}$ \\
\hline$g$ & $=$ acceleration of gravity \\
\hline $\boldsymbol{h}_{\mathrm{n}}$ & $=$ contact force vector between string and well bore \\
\hline$I$ & $=$ bending moment of inertia of string section \\
\hline$J$ & $=$ poplar moment of inertia of string section \\
\hline $\boldsymbol{k}$ & $=$ unit vector in the direction of gravitational field \\
\hline$k_{\mathrm{b}}$ & $=$ wellbore curvature \\
\hline$k_{\mathrm{n}}$ & $=$ wellbore torsion \\
\hline
\end{tabular}

$=$ string length

$=$ depth of the top packer

$=$ depth of the bottom packer

$=$ helical buckling end depth

$=$ helical buckling start depth

$=$ packer depth

$=$ depth of bottom of packer

$=$ depth of top of packer

$=$ depth of thermometer

$=$ well depth of calculation point

$=$ depth of packer $j$

$=$ depth of the top of packer $j$

$=$ depth of the bottom of packer $j$

$=$ torque on string

$=$ torque at the starting point for helical buckling

$=$ normal contact force between string and wellbore

$=$ contact force $\boldsymbol{h}_{\mathrm{n}}$ component in the direction of $\boldsymbol{e}_{\mathrm{b}}$

$=$ additional contact force for string buckling

$=$ contact force $\boldsymbol{h}_{\mathrm{n}}$ component in the direction of $\mathbf{e}_{\mathrm{n}}$

$=$ safety factor

$=$ downhole dynamic pressure

$=$ fluid pressure in string

$=$ fluid pressure in string at well head

$=$ internal pressure when the hydraulic anchor is opened

$=$ internal pressure when slips setting

$=$ fluid pressure in annulus

$=$ fluid pressure in annulus at wellhead

$=$ external pressure when the hydraulic anchor is opened

$=$ external pressure when slips setting

$=$ flow rate of liquid within string

$=$ flow rate of liquid in annulus

$=$ weight per unit length in the air

$=$ Reynolds number within string

$=$ Reynolds number in annulus

$=$ string inner radius

$=$ string outer radius

$=\left(R_{\mathrm{i}} \leq r \leq R_{\mathrm{o}}\right)$ is radius

$=$ radius difference between wellbore and string

$=$ axis displacement in depth of $l$

$=$ packer displacement in setting

$=$ top packer displacement in setting

$=$ bottom packer displacement in setting

$=$ packer displacement after internal and external pressure changed

$=$ stroke of slip

$=$ string temperature 


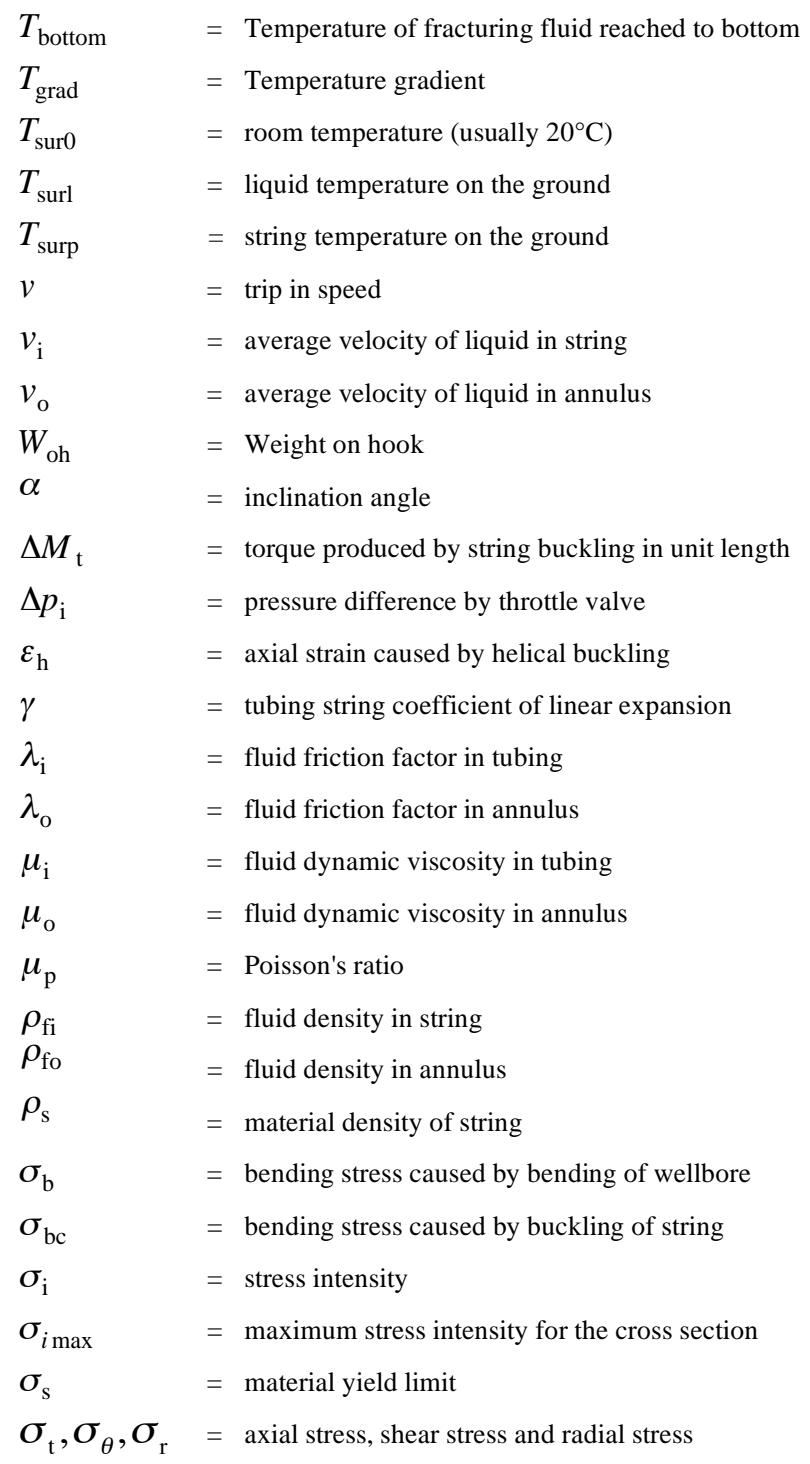
$\tau$
$\tau_{0}$
$\omega$

SI Unit is used.

\section{REFERENCES}

[1] J. L. Gidley, S. A. Holditch, D. E. Nierode, and R. W. V. Jr, Recent Advances in Hydraulic Fracturing.: The Richardson Society of Petroleum Engineers Inc: Richardson, 1989.

[2] Y. Zeng, X. Xing, Y. Cao, and F. Chen, "Study and application of fracturing \& production string with double packers in daniudi gas field", Journal of Southwest Petroleum University, vol. 29, no. 4, pp. 155-157, 2007.

[3] H. He, X. Li, Q. Hu, and F. Zhu, "Study of fracturing mechanism and test of hydraulic jetting with coiled tubing", China Petroleum Machinery, vol. 36, no. 4, pp. 1-4, 14, 2008.

[4] S. Tian, G. Li, Z. Huang, J. Niu, and Q. Xia, "Hydrojet- fracturing technology with coiled tubing", Natural Gas Industry, vol. 28, no. 8, pp. 61-63, 2008.

[5] E. Kuru, A. Martinez, S. Miska, and W. Qiu, "The buckling behavior of pipes and its influence on the axial force transfer in directional wells", Journal of Energy Resources Technology, vol. 122, pp. 129-135, 2000.

[6] X. Du, H. Wang, S. Wang, and J. Liu, "Mechanics analysis of down hole string used for deep well fracturing and its application", Oil Field Equipment, vol. 37, no. 8, pp. 28-33, 2008.

[7] Z. Wang, W. Li, and Y. Xu, "Analysis on stress distribution of fracturing string with finite element method in deep gas well", Science Technology and Engineering, vol. 9, no. 2, pp. 409-412, 2009.

[8] Z. Li, J. Dai, and Z. Yu, "Mechanical analysis of downhole strings for two-layer fracturing and its application", Oil Drilling \& Production Technology, vol. 31, no. 1, pp. 81-84, 2009.

[9] E. Yuan, Engineering Fluid Mechanics Petroleum Industry Press:, Beijing, 1986.

[10] Z. Li, Tubular Mechanics in Oil-Gas Wells and Its Applications.: Petroleum Industry Press: Beijing, 2008.

[11] J. Li, Z. Li, T. Li, C. Wang, G. Li, and H. Zhu, "Mechanical analysis software of down hole operation pipe strings and its application”, Petroleum Drilling \& Production Technology, vol. 30, no. 5, pp. 118- 121, 2008.

(C) Li and Li; Licensee Bentham Open.

This is an open access article licensed under the terms of the Creative Commons Attribution Non-Commercial License (http://creativecommons.org/licenses/by-nc/3.0/) which permits unrestricted, non-commercial use, distribution and reproduction in any medium, provided the work is properly cited. 